\title{
Potential reduction in urban runoff by green spaces in Beijing: A scenario analysis
}

\author{
Lei Yao ${ }^{\mathrm{a}, \mathrm{b}}$, Liding Chen ${ }^{\mathrm{a}}$, Wei Wei ${ }^{\mathrm{a}, *}$, Ranhao Sun ${ }^{\mathrm{a}}$ \\ a State Key Laboratory of Urban and Regional Ecology, Research Center for Eco-Environmental Sciences, Chinese Academy of Sciences, Shuangqing Road 18, \\ Haidian District, Beijing 100085, China \\ ${ }^{\mathrm{b}}$ University of Chinese Academy of Sciences, Yuquan Road 19, Shijingshan District, Beijing 100049, China
}

\section{A R T I C L E I N F O}

\section{Keywords:}

Curve number method

Rainwater management

Urban flooding

Urban planning

\begin{abstract}
A B S T R A C T
Urban green space provides multiple ecological benefits, among which the reduction of rainfall runoff is important for sustainable urban development, particularly for cities experiencing severe flooding and water hazards. However, the effectiveness of urban green space in mitigating runoff has not been fully determined. We evaluated potential reductions in surface runoff associated with urban green space in central Beijing under a greening scenario using the Soil Conservation Service Curve Number method. The results show that urban green space offers significant potential for runoff mitigation. In 2012, a total of 97.9 million $\mathrm{m}^{3}$ of excess surface runoff was retained by urban green space; adding nearly $11 \%$ more tree canopy was projected to increase runoff retention by $>30 \%$, contributing to considerable benefits of urban rainwater regulation. At a more detailed scale, there were apparent internal variations. Urban function zones with $>70 \%$ developed land showed less mitigation of runoff, while green zones (vegetation $>60 \%$ ), which occupied only $15.54 \%$ of the total area, contributed $31.07 \%$ of runoff reduction. Runoff reduction by urban green space, however, is influenced by many factors, such as rainfall, soil condition, and urban morphology. In regulating urban runoff, therefore, the priorities and integrating adaptive approaches to urban greening should be combined with compensatory and complementary measures.
\end{abstract}

(C) 2015 Elsevier GmbH. All rights reserved.

\section{Introduction}

Urbanization, a key feature of global population growth, is inextricably related to land use and cover changes (LUCC) (Jha et al., 2012). A dominant feature of LUCC in urban areas is a mosaic pattern of impervious surfaces and green spaces. An increase in impervious surfaces can significantly alter natural hydrological processes, inhibiting rainwater infiltration and increasing surface runoff and peak discharge rates (Leopold, 1968; Whitford et al., 2001; Paul and Meyer, 2001). Under similar rainfall conditions, $>40 \%$ of rainfall can be converted to surface runoff in urban landscapes with $>50 \%$ impervious surfaces, whereas runoff in woodland areas may be as low as $13 \%$ (Bonan, 2002). Greater runoff in urban areas adversely affects local biogeochemical cycles, and poses threats to life and property as well as the sustainable development of cities (Walsh et al., 2005; Pataki et al., 2011).

\footnotetext{
* Corresponding author. Tel.: +86 10 62918673; fax: +86 1062918673.

E-mail addresses: alex_yaolei@126.com (L. Yao), liding@rcees.ac.cn (L. Chen), weiwei@rcees.ac.cn (W.Wei), rhsun@rcees.ac.cn (R. Sun).
}

However, urban green space, consisting of tree canopy, lawns, and farmland (Beijing Municipal Commission of Urban Planning, 2009), positively influences urban hydrology through soil-water storage and enhanced infiltration into the root and soil zones, as well as interception by the canopy and plant stems (Gill et al., 2007; Zhang et al., 2012). Through laboratory and field experiments in urban areas, green space has been found to be effective in retaining runoff (Yang et al., 2013). Similarly, Armson et al. (2013) demonstrated that a single "tree unit" (a single tree and its pit) reduced surface runoff by $>50 \%$ annually compared with asphalt. On a larger scale, afforestation results in significant reductions in runoff and sediment yield within urban catchments (Sanders, 1986; Matteo et al., 2006). In general, urban green space acts as an effective sink for receiving and storing rainwater and as an important element of urban water management. Urban green space also confers a wide range of "eco-services," including local climate regulation and environmental purification, habitat and biodiversity, productivity through photosynthesis, information and esthetic experiences, and carrier functions such as biogenic migration, among others (Roy et al., 2012), which are indispensable for the urban environment and local residents. Given its multiple benefits, widespread attention has been given to the construction and preservation of urban 
green space as an effective approach for relieving crises of urban water resource and improving the quality of the urban environment. The positive role of urban green space in terms of public welfare should also be considered by city managers and the public (Van Herzele and Wiedemann, 2003).

Although several researchers have studied the effects of green spaces on reducing runoff, most previous studies have focused on gross volumes (Reid et al., 1999; Xiao and McPherson, 2002; Van Herzele and Wiedemann, 2003; Zhang et al., 2010). Thus, few investigations to date have evaluated fine-scale variations in surface runoff reduction associated with the urban landscape and greening. Owing to clustered and unplanned development of urban areas, urban resources (including ecological, social, and economic resources) are disproportionately distributed within urban areas. Thus, urban function zones (UFZs) have been defined to characterize the spatial patterns of a city in relation to its urban functions (Tian et al., 2010). Each type of UFZ is comprised of several zones with the same urban function. Each zone is organized by a cluster type of land uses, and its function is determined by the dominant land use. UFZs can reflect the urban landscape planning concerns, and effectively combine urban spatial pattern with urban resources and human activities such as dwellings, education, commerce, and industry (Gill et al., 2007; Sun et al., 2013). With increasing rainfall-related surface runoff, UFZs are subjected to differing risk according to their distinctive spatial arrangements and availability of resources. This phenomenon has generally been overlooked. Moreover, green planning schemes for urban rainwater management generally establish overall goals rather than more detailed objectives for specific areas. In Beijing, for example, the municipality has established a goal of $40 \%$ total greening of the city center by 2020 , but most of this increase will be concentrated in existing green space because of the relative ease of implementation (Beijing Municipal Commission of Urban Planning, 2009). In contrast, green spaces in urban built-up areas will not be fully complemented, which may cause the rainwater management in these areas cannot be well covered by the greening project. Therefore, knowledge of the potential effects urban greening on runoff reduction at multiple scales, from the urban functional scale to the entire urban region, may provide valuable guidance to policy-makers and city managers regarding urban runoff management.

In this study, we combined GIS and remote sensing technology with a widely used hydrologic model, to simulate the effects of urban green space on runoff reduction in a highly urbanized area of Beijing. The study had several goals: (1) to examine the effects of urban green space on runoff reduction at multiple scales (i.e., the whole study area and UFZ scale), (2) to evaluate the benefits of future green planning on runoff regulation, and (3) to explore potential factors in the reduction of rainfall runoff by urban green space.

\section{Methods}

\section{Study area}

Beijing is located at $39^{\circ} 26^{\prime}-41^{\circ} 03^{\prime} \mathrm{N}, 115^{\circ} 25^{\prime}-117^{\circ} 30^{\prime} \mathrm{E}$. The permanent population of Beijing was 20 million in 2011, with a population density of about $1230 \mathrm{~km}^{-2}$ (Beijing Statistical Bureau, 2012). The city has a temperate monsoon climate, with an average temperature of $12^{\circ} \mathrm{C}$ and distinct seasons. From 1978 to 2011, the average precipitation in Beijing was $542.6 \mathrm{~mm} / \mathrm{year}$, with rainfall concentrated in the summer (Beijing Statistical Bureau, 2012).

As the political, cultural, and economic center of China, Beijing has undergone rapid urbanization. From 1973 to 2005, the developed area of the city expanded from 183.8 to $1209.9 \mathrm{~km}^{2}$ at an average rate of $32.1 \mathrm{~km}^{2} /$ year (Mu et al., 2007). Owing to this rapid urbanization, rainfall-induced floods in Beijing have become more frequent. Beijing suffered a particularly serious flood in the summer of 2012, causing 78 deaths and enormous economic losses. This event resulted in greater concern over urban flooding risks citywide, and a series of environmental management policies were released to address the issue (Pan et al., 2009). Thus, for both science and policy reasons, the highly urbanized region within the fifth ring road of Beijing, covering nearly $667.1 \mathrm{~km}^{2}$, was chosen as the study area (Fig. 1).

\section{Spatial identification}

An IKONOS image with four spectral bands was used to extract land-cover information within the fifth ring road region of Beijing. The image was captured in summer (29 July 2012), in order to provide information on vegetation. The image was georeferenced to a common UTM map base with a first-order polynomial transformation. For higher spatial resolution, the $4 \mathrm{~m}$ spectral bands were pan-sharpened to $1 \mathrm{~m}$ with a monochrome image prior to classification. The object-oriented method was adopted to classify land-cover types. We partitioned the remote sensing image into segments (in terms of "objects") by grouping neighboring pixels with similar feature values. A set of characteristic parameters for each object (i.e., spatial, textural, spectral, color, and band ratio) was compiled and then transferred to multiple rule sets. With leaf-on images, it is difficult to characterize land surface cover beneath the tree canopy. Considering the substantial capacities of tree leaves and branches to intercept rainfall, vegetation coverage overlapping impervious surfaces was treated as tree canopy (Inkiläinen et al., 2013). Geo-body shadows were sub-selected into actual cover types using manual and machine classification processes (Chen et al., 2014). Ultimately, we extracted six types of land cover using the rule-based classification method: developed land, water bodies, farmland, tree canopy, lawns, and bare land (Fig. 1). Ground-truthing analysis was conducted by verifying 387 random points after classification. The overall precision was $85.8 \%$ and the kappa coefficient was 0.75 .

To explore the amounts and distribution patterns of runoff reduction by urban green space, we used a more detailed spatial scale (Sanders, 1986; Carter and Jackson, 2007). We defined an urban function block (UFB) as a finer sub-area (similar to an urban block) within a UFZ, to explore the detailed distribution of runoff reduction by urban green space. First, we manually delineated the entire study area into mesh regions (i.e., UFBs) along with urban roads and canal networks. Considering that linear landscape elements in urban areas typically serve as the borders of urban functional units as well as subareas of urban sewer systems, this partitioning method not only produced detailed information on urban functional units but also classified each UFB as an independent hydrological unit. Next, referring to the definitions of UFZs in Beijing by Sun et al. (2013), we grouped the study area into 11 types of UFZs: high-density residential zone (HRZ), low-density residential zone (LRZ), government zone (GOZ), industry zone (INZ), commercial zone (COZ), recreational zone (REZ), preservation zone (PRZ), agricultural zone (AGZ), public service zone (PSZ), development zone (DEZ), and open water (WTR). Each UFB was then geocoded with a specific functional type according to its architectural/landscape and social function characteristics (Table 1). Detailed spatial and social information for these UFBs was mainly identified using high-resolution images and the Internet (e.g., Google Maps) on a desktop computer. Field verification was also conducted for indeterminate UFBs. Ultimately, 5116 UFBs were identified and a detailed map was digitized (Fig. 1). Spatial data, such as the total green space area (TGA) within UFBs and UFZs, were summarized using GIS spatial analyses. 


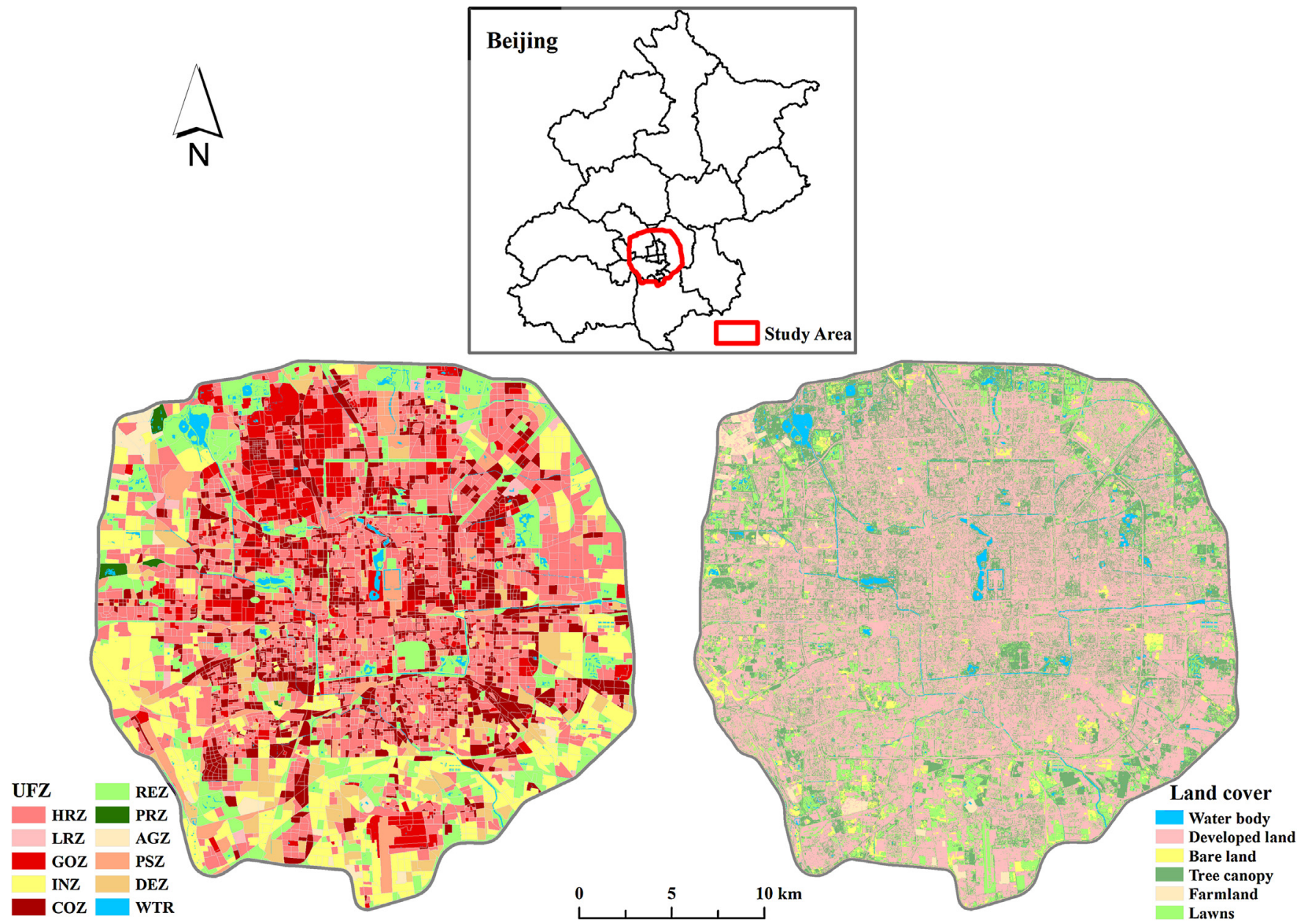

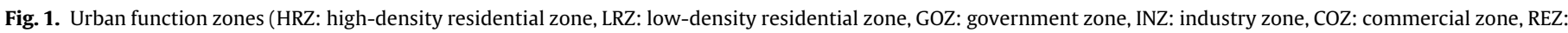
recreational zone, PRZ: preservation zone, AGZ: agricultural zone, PSZ: public service zone, DEZ: development zone, and WTR: open water) and land cover.

\section{Model preparation}

Our study focused on the general potential benefits of urban green space for reducing rainfall runoff across a large urban area. A cost-effective hydrologic model, the Soil Conservation Service
Curve Number (SCS-CN) model, was thus selected for calculating the volume of runoff reduction by urban green space in our study area. The SCS-CN method has been used for a wide range of watershed areas, from 0.25 ha to $1000 \mathrm{~km}^{2}$, and applied to various climatic zones (Boughton, 1989; Ebrahimian et al., 2012; El-Hames,

Table 1

Urban function zones (UFZs) within the Beijing fifth ring road.

\begin{tabular}{|c|c|c|c|}
\hline UFZ & Abbreviation & Area (ha) & Description \\
\hline High-density residential zone & HRZ & $21,187.9$ & $\begin{array}{l}\text { Services for citizens; typical residential communities in Beijing, } \\
\text { including low-rise and high-rise buildings with dense population. }\end{array}$ \\
\hline Low-density residential zone & LRZ & 450.0 & $\begin{array}{l}\text { Services for citizens; lower impervious fraction; mainly low-rise } \\
\text { buildings with sparse population. }\end{array}$ \\
\hline Government zone & GOZ & 6119.2 & $\begin{array}{l}\text { Services for civil servants and students; government buildings, public } \\
\text { organizations, research institutes, and campuses. }\end{array}$ \\
\hline Industry zone & INZ & 9460.1 & $\begin{array}{l}\text { Services for production workers and laborers; city infrastructure and } \\
\text { industrial factories, energy, and resources supply. }\end{array}$ \\
\hline Commercial zone & $\mathrm{COZ}$ & $10,100.6$ & $\begin{array}{l}\text { Services for business and commercial workers; city malls, retail } \\
\text { businesses, and public amenities such as restaurants, hotels, etc. }\end{array}$ \\
\hline Recreational zone & REZ & 9204.5 & $\begin{array}{l}\text { Services for tourists and residents; urban parks, golf courses, and } \\
\text { scenic areas with relatively high green coverage. }\end{array}$ \\
\hline Preservation zone & PRZ & 225.1 & $\begin{array}{l}\text { Services for tourists and residents; open space with natural and } \\
\text { artificial green space such as forest parks. }\end{array}$ \\
\hline Agricultural zone & AGZ & 751.9 & $\begin{array}{l}\text { Services for agricultural workers; cultivated land, greenhouses, and } \\
\text { orchards. }\end{array}$ \\
\hline Public service zone & PSZ & 3704.6 & $\begin{array}{l}\text { Services for citizens, such as hospitals, libraries, museums, stadiums, } \\
\text { and city squares. }\end{array}$ \\
\hline Development zone & DEZ & 4302.1 & $\begin{array}{l}\text { Services mainly for construction workers; undeveloped open space } \\
\text { and demolition areas. }\end{array}$ \\
\hline Open water & WTR & 1203.8 & Open water, including lakes, ponds, rivers, and ditches. \\
\hline
\end{tabular}


2012; Baker and Miller, 2013). The SCS-CN model has been used with agricultural watersheds and also functions well in urban areas. Many urban ecohydrology studies have used this model to simulate various runoff scenarios, ranging from small urban sites (e.g., highway or residential lots) to neighborhoods to large urban watersheds (Tsihrintzis and Hamid, 1997; Brander et al., 2004; Sjöman and Gill, 2013).

This model is based on empirical studies of ungauged watersheds to estimate runoff from rainfall events (NRCS, 1986). Minimal input data are needed to simulate direct surface runoff. Specifically, the calculations require only rainfall abstraction, without considering other complex factors (e.g., groundwater recharge and base flow). Three parameters are used to calculate surface runoff: rainfall depth, initial abstraction of the rainfall, and the potential maximum storage of the soil (Boughton, 1989). The equations for the SCS-CN model are as follows (NRCS, 1986):

$Q= \begin{cases}\left(P-I_{\mathrm{a}}\right)^{2} /\left(P-I_{\mathrm{a}}+S\right), & P \geq I_{\mathrm{a}} \\ 0, & P<I_{\mathrm{a}}\end{cases}$

$S=\frac{25,400}{C N}-254$

$I_{\mathrm{a}}=\lambda \cdot S$

where $Q$ is the runoff depth ( $\mathrm{mm}), P$ the rainfall depth ( $\mathrm{mm}), I_{\mathrm{a}}$ the initial abstraction of the rainfall $(\mathrm{mm})$, and $S$ represents potential maximum soil-water capacity. The initial abstraction coefficient $\lambda$ is a constant, usually defined as 0.2 (El-Hames, 2012; Kadam et al., 2012; Singh et al., 2013), and $C N$ is a dimensionless parameter, ranging from 0 to 100 . The US Natural Resources Conservation Service (NRCS) has developed $C N$ values for various land-cover categories based on their hydrologic characteristics. A higher $C N$ value indicates greater potential for surface runoff as well as reduced infiltration and less surface storage of rainwater; thus, the $C N$ value for impervious surfaces is higher than that for plant canopies. As the above equations illustrate, calculation of surface runoff in this model requires only rainfall data and $C N$ values.

Daily rainfall data for Beijing in 2012 were used to calculate runoff (China Meteorological Administration, 2012). Annual precipitation was $733.2 \mathrm{~mm}$ and there were 74 days with rainfall events during the year. The maximum and minimum rainfall depths were 82.9 and $0.1 \mathrm{~mm}$, respectively.

Determination of the $C N$ value for the SCS-CN model mainly depends on the corresponding hydrologic soil group (HSG), landcover type, and antecedent moisture condition (AMC). Based on the minimum infiltration rates for various soil textures, NRCS divides soils into four HSGs (A, B, C, and D) (NRCS, 1986). Group A has the lowest runoff potential and the highest infiltration capacity, whereas soils in Group D have the highest runoff potential and the lowest infiltration capacity. Groups B and C have moderate infiltration capacities. Data for the HSG in our study area were obtained from Fu et al. (2013), who measured soil infiltration characteristics in Beijing, including our study area. In their study, 51 soil sampling plots representative of all the soil types of Beijing were placed in areas with different types of cover, including tree canopy, lawns, and farmland. Six soil samples were collected within each plot. The saturated hydraulic conductivities of the soil samples were measured using the invariable water-level method. The mean saturated hydraulic conductivities measured for Beijing ranged from 44 to $166 \mathrm{~mm} / \mathrm{h}$; therefore, they concluded that the HSG within most areas of Beijing was B (defined as $18-180 \mathrm{~mm} / \mathrm{h}$ ).

NRCS classified AMCs as "dry conditions" (AMC I), "moderate/normal conditions" (AMC II), and "wet conditions" (AMC III) to represent the relative moisture of the pervious surfaces prior to the rainfall event (NRCS, 1986). CN value of a specific land cover with AMC III is higher than that with AMC I, indicating that underlying
Table 2

Curve Numbers $(\mathrm{CN})$ for urban green space in different antecedent moisture conditions (AMC).

\begin{tabular}{llll}
\hline Urban green space & AMC I & AMC II & AMC III \\
\hline Farmland & 60 & 78 & 90 \\
Tree canopy & 37 & 58 & 78 \\
Lawns & 40 & 61 & 80 \\
\hline
\end{tabular}

surface with wetter soil moisture condition is prone to generate more runoff. The classification method of AMC can effectively avoid the underestimation on runoff calculation due to the various soil moisture conditions of rainfall events (NRCS, 1986; Xiao and McPherson, 2002). Therefore, the AMC of each rainfall event was determined depending on rainfall amount during the previous 5 days and the season, and all the daily rainfall data were regrouped for runoff calculation. Accordingly, in 2012, 45 rainfall events were grouped as AMC I, seven events as AMC II, and 22 events as AMC III.

Because our research was focused on the hydrological benefits of green space in urban areas, only the three types of land cover representing urban green space (i.e., tree canopy, lawns, and farmland) were included in the calculations for our study area. For each pixel, $100 \%$ single-cover coverage was assumed due to the relatively high-spatial resolution, so that a unique $C N$ value was assigned to each type of urban green space (Reistetter and Russell, 2011; Atkinson, 2012; Fan et al., 2013). Finally, the $C N$ values for urban green space in different AMCs were determined using the TR-55 look-up tables (NRCS, 1986) (Table 2). A CN of 98 was assigned to represent the hydrologic characteristics of $100 \%$ impervious surfaces for the runoff reduction calculation.

\section{Runoff reduction calculation}

Based on Zhang et al. (2012), the reduction of surface runoff was characterized as that achieved by replacing fully impervious surfacing with urban green space. Two variables were defined to evaluate the potential hydrologic benefits of runoff reduction: the total amount of runoff reduction by urban green space $\Delta V$ and the runoff reduction coefficient $C_{\mathrm{r}}$.

$\Delta V$ (as defined by Zhang et al., 2012) was used to represent differences in total runoff reduction volume and characterize the general benefit provided by urban green space in terms of reducing rainfall-runoff. $C_{r}$ is similar to the runoff coefficient (runoff depth/rainfall depth) (Weng, 2001; Costa et al., 2003) and was generated by dividing $\Delta V$ by the total amount of rainfall in a specific area (e.g., a UFZ or UFB). Unlike $\Delta V, C_{\mathrm{r}}$ represents differences in runoff reduction efficiency. A higher $\Delta V$ means greater potential hydrologic benefits provided by urban green space, whereas a higher $C_{\mathrm{r}}$ indicates less need to improve future urban rainwater management in a specific area.

$\Delta V$ was calculated as follows:

$\Delta V=\sum_{i=1}^{3} 0.001 \cdot\left(Q_{b}-Q_{i}\right) \cdot A_{i}$

where $\Delta V$ is the runoff reduction $\left(\mathrm{m}^{3}\right)$ due to urban green space, $i$ the type of urban green space (tree canopies: $i=1$; lawn: $i=2$; farmland: $i=3), Q_{b}$ the runoff depth $(\mathrm{mm})$ generated from a $100 \%$ impervious surface with a $C N$ value of $98, Q_{i}$ the runoff depth (mm) from urban green space type $i$, and $A_{i}$ is the area $\left(\mathrm{m}^{2}\right)$ of urban green space type $i$ within a study unit at various spatial scales (i.e., the entire study area, UFZs, and UFBs).

$C_{\mathrm{r}}$ was calculated as follows:

$C_{\mathrm{r}}=\Delta V \cdot(0.001 \cdot P \cdot A)^{-1}$ 
where $C_{\mathrm{r}}$ is the runoff reduction coefficient, $P$ the daily rainfall depth $(\mathrm{mm})$, and $A$ the area $\left(\mathrm{m}^{2}\right)$ of a study unit at various spatial scales (i.e., the entire study area, UFZs, and UFBs).

\section{Greening scenario design}

A green planning scenario was developed to explore the potential benefits of runoff regulation in future urban landscape planning. Based on the overall goal for urban green space planning for Beijing (Beijing Municipal Commission of Urban Planning, 2009), we increased green coverage within the UFBs to $40 \%$, where green coverage is currently $<40 \%$. Runoff reduction by urban green space, under the existing and greening scenario, were estimated in spreadsheet models using Eqs. (4) and (5).

\section{Results}

Spatial pattern of urban green spaces

Spatial analysis revealed that $34.46 \%$ of the study area comprised green space (22,998.7 ha), of which tree canopies contributed 22.27, lawns 11.30 , and farmland $0.91 \%$. At the scale of the UFZs, TGA was unevenly distributed (Table 3 ). The REZ and HRZ contributed the most TGA, at 6511.7 and 5977.7 ha, respectively, followed by INZ, GOZ, COZ, DEZ, PSZ, AGZ, and LRZ, while PRZ made up the lowest TGA of 162.6 ha. At the higher spatial resolution of the UFBs, the percent green space varied considerably (Table 3 ). The lower end of the range within each UFB type was nearly zero, except for PRZ and AGZ. UFBs in COZ had the lowest percent green space, but the widest range of $0-78.15 \%$. In contrast, UFBs in PRZ had the highest average percent green space and the narrowest range (61.63-87.97\%). Moreover, most of the farmland was included in AGZ and had a relatively high percent green space. Within AGZ, some UFBs showed lower percentages owing to the presence of agricultural greenhouses and rural residences. LRZ occupied a relatively small total area, but the percent green space was higher in these UFBs than in those of the HRZ. With the exception of REZ UFBs (60\%), other types of UFBs had similar average green space (about $25 \%)$.

Within the entire study area, the TGA increased under the greening scenario by $11.41 \%(30,611.5 \mathrm{ha})$. TGA increases were evident for all UFZs to varying degrees. The TGAs for some UFZs, such as COZ, HRZ, INZ, DEZ, PSZ, and GOZ, showed substantial increases of $>25 \%$. In particular, compared to the current situation, the TGA for $\mathrm{COZ}$ nearly doubled (98.89\% increase) after greening. Notably, changes in the other UFZs were all $<5 \%$, implying that these UFZs had less potential for future urban greening. Overall, 4139 of the 5116 UFBs showed increased virescence under the greening scenario; percent green area increases for the UFBs were similar to those for the UFZs (Table 3).

\section{Runoff reduction by urban green space}

With these increases in TGA under the urban greening scenario, $\Delta V$ increased correspondingly. Under the current situation, annual $\Delta V$ by green spaces within the entire study area was 97.9 million $\mathrm{m}^{3}$ or $4258 \mathrm{~m}^{3} /$ ha green space (ratio between the annual $\Delta V$ and the total area of green space). Increased tree cover reduced total surface runoff by 131.0 million $\mathrm{m}^{3}$. Furthermore, the annual runoff reduction coefficient $C_{\mathrm{r}}$ of the base scenario was 0.20 , whereas that for the greening scenario increased to 0.27 .

The results of the SCS-CN simulation were then categorized by daily rainfall depth and AMC. It was found that both precipitation and AMC strongly affected $\Delta V$ and $C_{\mathrm{r}}$. In the current situation, urban green space showed greater mitigation of surface runoff under conditions of increased precipitation (Fig. 2). The maximum $\Delta V$ of 9.6

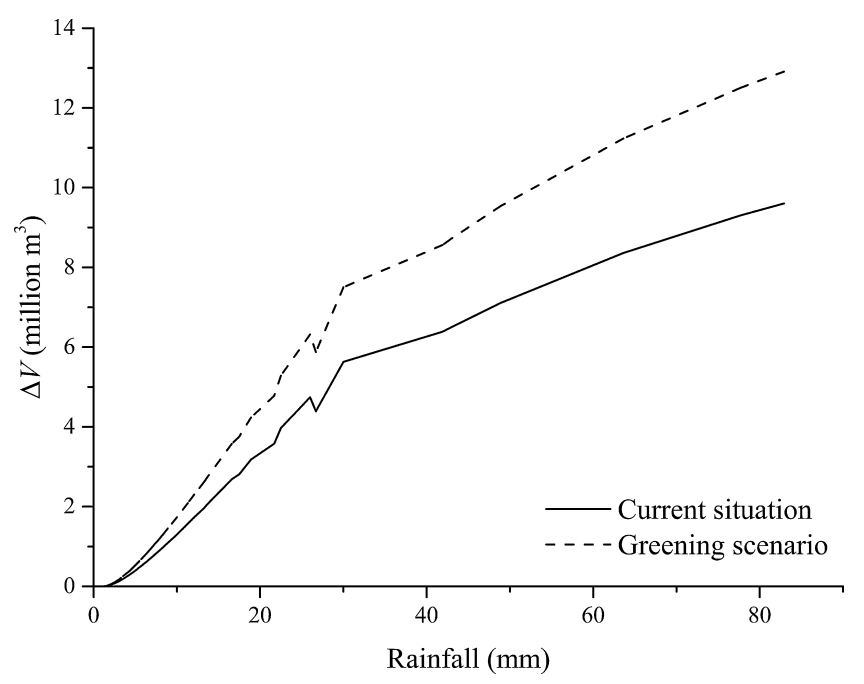

Fig. 2. Runoff reduction $\Delta V$ with increasing rainfall.

million $\mathrm{m}^{3}$, occurred during the heaviest rainfall event of $82.9 \mathrm{~mm}$ on 22 July 2012 . For the greening scenario, the trend in $\Delta V$ was consistent with that for the current situation. $\Delta V$ was $233.5 \mathrm{~m}^{3}$ for the $1.1 \mathrm{~mm}$ rainfall event and 12.9 million $\mathrm{m}^{3}$ for the heaviest rainfall event, representing an increase in $\Delta V$ of approximately $33 \%$ compared with the current situation.

The effect of AMC on $\Delta V$ is shown in Fig. 3. Although the overall trend was the same as that discussed above, there was an anomaly between the rainfall events of 26.0 (12 August 2012) and $26.7 \mathrm{~mm}$ (24 April 2012), in which the $\Delta V$ of the former $\left(4.7\right.$ million $\mathrm{m}^{3}$ ) was greater than that of the latter $\left(4.4\right.$ million $\left.\mathrm{m}^{3}\right)$. This was attributed to the differing AMC classifications for these two rainfall events (AMC I for the $26.0 \mathrm{~mm}$ event and AMC III for the $26.7 \mathrm{~mm}$ event).

In contrast to the trend in runoff reduction, $C_{\mathrm{r}}$ first increased sharply then decreased gradually with increasing rainfall for both scenarios (Fig. 4). The lowest $C_{\mathrm{r}}$ (nearly 0 ) occurred for the $1.1 \mathrm{~mm}$ rainfall event, then $C_{\mathrm{r}}$ increased with rainfall, and reached its maximum value $(0.29$ for the current situation and 0.38 for the greening scenario) when rainfall depth reached $30 \mathrm{~mm}$. After that, $C_{\mathrm{r}}$ decreased as rainfall depth increased. Rainfall events with different AMC classifications showed differing relationships between $C_{\mathrm{r}}$ and rainfall (Fig. 5). $C_{\mathrm{r}}$ with AMCs I and II showed a

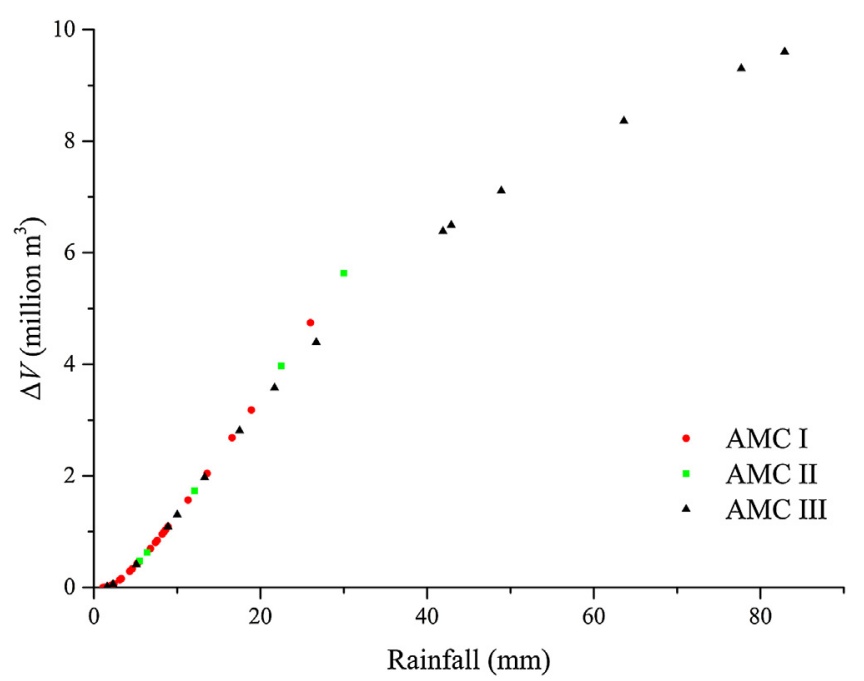

Fig. 3. Runoff reduction $\Delta V$ with increasing rainfall under different antecedent moisture conditions. 
Table 3

Total green space area (ha) of urban function zones (UFZs) and the percent green space variations (mean \pm standard deviation, \%) within each UFZ.

\begin{tabular}{|c|c|c|c|c|}
\hline & \multicolumn{2}{|l|}{ UFZ scale } & \multicolumn{2}{|l|}{ UFB scale } \\
\hline & Current situation & Greening scenario & Current situation & Greening scenario \\
\hline LRZ & 234.2 & 245.7 & $48 \pm 16$ & $52 \pm 11$ \\
\hline HRZ & 5977.7 & 8656.0 & $27 \pm 10$ & $41 \pm 3$ \\
\hline INZ & 2792.0 & 4086.0 & $25 \pm 17$ & $42 \pm 7$ \\
\hline DEZ & 1306.5 & 1911.3 & $28 \pm 21$ & $45 \pm 10$ \\
\hline PSZ & 1280.8 & 1684.7 & $26 \pm 15$ & $42 \pm 6$ \\
\hline GOZ & 2093.2 & 2628.2 & $27 \pm 12$ & $41 \pm 5$ \\
\hline AGZ & 573.1 & 577.6 & $78 \pm 18$ & $78 \pm 16$ \\
\hline REZ & 6511.7 & 6548.6 & $60 \pm 19$ & $62 \pm 16$ \\
\hline $\mathrm{COZ}$ & 2066.9 & 4110.9 & $19 \pm 11$ & $40 \pm 2$ \\
\hline PRZ & 162.6 & 162.6 & $76 \pm 11$ & $76 \pm 11$ \\
\hline
\end{tabular}

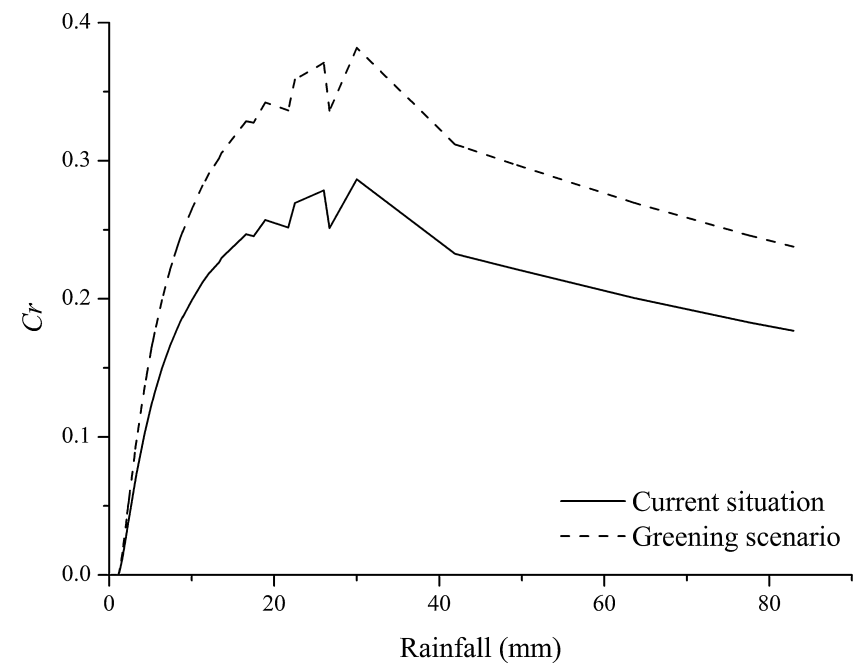

Fig. 4. Runoff reduction coefficient $C_{\mathrm{r}}$ with increasing rainfall.

steady increasing trend when rainfall depth increased, whereas $C_{\mathrm{r}}$ for AMC III increased at first and dropped later. Additionally, urban green space with AMCs I and II had higher $C_{\mathrm{r}}$ values than with AMC III after rainfall exceeded $21.7 \mathrm{~mm}$.

In-depth spatial evaluations at the UFZ scales revealed more details of the runoff reduction patterns. Under the current scenario, the highest annual $\Delta V$ was found for REZ with 27.9 million $\mathrm{m}^{3}$, followed by HRZ with 25.7 million $\mathrm{m}^{3}$ (Table 4). As PRZ occupied a

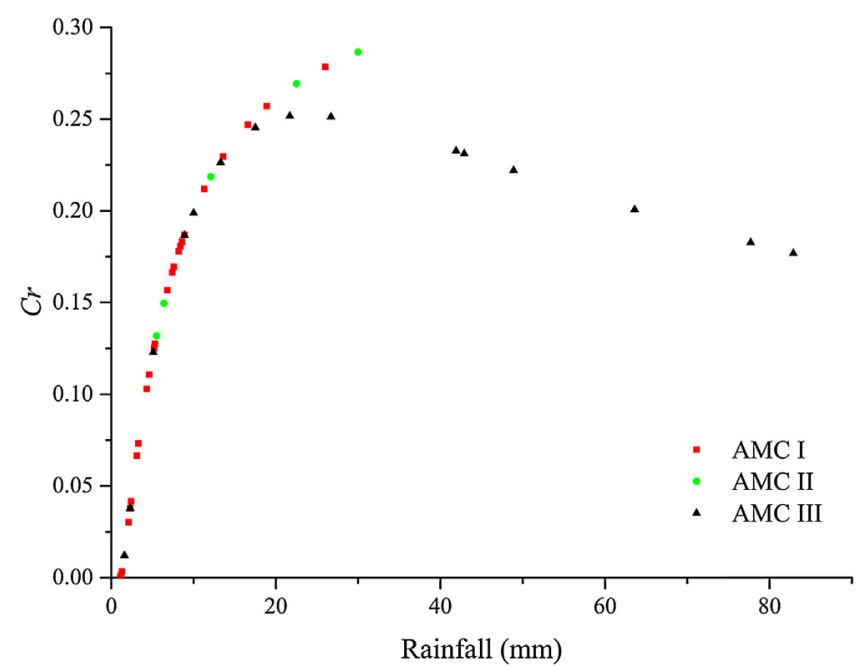

Fig. 5. Runoff reduction coefficient $C_{\mathrm{r}}$ with increasing rainfall under different antecedent moisture conditions. (a)

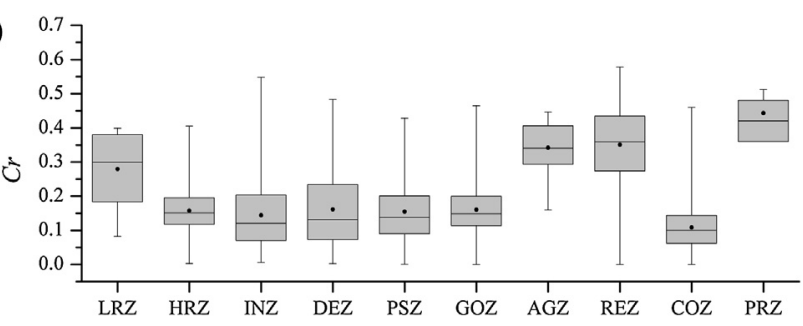

(b)

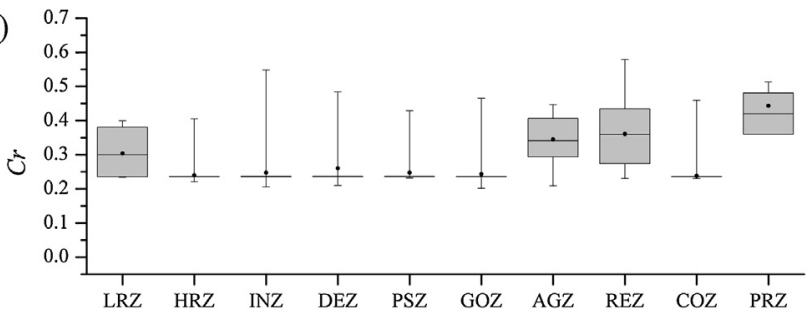

Fig. 6. Runoff reduction coefficient $C_{\mathrm{r}}$ variations in urban function zones under (a) the current situation and (b) the greening scenario (zones as defined in Fig. 1).

relatively small fraction of the total area, it had the highest percentage of green cover but the lowest $\Delta V . \Delta V$ for the remaining UFZs together accounted for $<15 \%$ of the total. Under the greening scenario, the order of $\Delta V$ changed. Annual $\Delta V$ was highest in $\mathrm{COZ}$ and HRZ, at 8.9 and 11.6 million $\mathrm{m}^{3}$, respectively. INZ, DEZ, PSZ, and $\mathrm{GOZ}$, with smaller percentages of green space, also showed significant increases. Consistent with the lack of change in TGA, the $\Delta V$ of PRZ showed little change.

The rank ordering of $C_{\mathrm{r}}$ among the UFZs differed from that for the runoff reduction volume (Table 4). Although showing the smallest reduction in surface runoff, PRZ had the highest reduction efficiency, with a consistent $C_{\mathrm{r}}$ value of 0.42 for both scenarios. Under the current situation, REZ, AGZ, and LRZ also had relatively high $C_{\mathrm{r}}$ values of $>0.3$ compared with the other UFZs (i.e., COZ, HRZ, INZ, PSZ, GOZ, and DEZ), which had relatively low $C_{\mathrm{r}}$ values of $<0.2$. After greening, the $C_{\mathrm{r}}$ values for all of the UFZs were $>0.2$, a reflection of positive changes in the TGA under the greening scenario.

Large variations were present within each UFZ, mainly resulting from different percentages of green space. Green space within one UFB of REZ reduced the maximum runoff by 1.0 million $\mathrm{m}^{3}$ annually, whereas no runoff reduction was observed for some UFBs in GOZ, REZ, and COZ. The lowest $\Delta V$ for each UFZ increased somewhat in the greening scenario.

The annual runoff reduction coefficient $C_{\mathrm{r}}$ ranged from 0 to 0.57 at the UFB scale, depending on the percentage of green coverage within each UFB (Fig. 6). For example, in COZ, with the lowest average $C_{\mathrm{r}}$, one UFB provided no $\Delta V$ in the current scenario because the site was occupied by a large city mall without any green space. However, a different UFB within $\mathrm{COZ}$ had a high $C_{\mathrm{r}}$ value of 0.46 because it had greater vegetation coverage despite 
Table 4

Runoff reduction volume $\Delta V\left(\right.$ million $\left.\mathrm{m}^{3}\right)$ and runoff reduction coefficient $C_{\mathrm{r}}$ for urban function zones.

\begin{tabular}{|c|c|c|c|c|c|c|c|c|c|c|c|}
\hline & & LRZ & HRZ & INZ & DEZ & PSZ & $\mathrm{GOZ}$ & AGZ & REZ & $\mathrm{COZ}$ & PRZ \\
\hline \multirow{2}{*}{ Current situation } & $\Delta V$ & 1.0 & 25.7 & 11.9 & 5.5 & 5.5 & 9.0 & 1.8 & 27.9 & 8.9 & 0.7 \\
\hline & $C_{\mathrm{r}}$ & 0.30 & 0.17 & 0.17 & 0.18 & 0.20 & 0.20 & 0.33 & 0.41 & 0.12 & 0.42 \\
\hline \multirow{2}{*}{ Greening scenario } & $\Delta V$ & 1.1 & 37.3 & 17.5 & 8.2 & 7.2 & 11.3 & 1.8 & 28.1 & 17.8 & 0.70 \\
\hline & $C_{\mathrm{r}}$ & 0.32 & 0.24 & 0.25 & 0.26 & 0.27 & 0.25 & 0.33 & 0.42 & 0.24 & 0.42 \\
\hline
\end{tabular}

being designated for commercial use. These variations in $C_{\mathrm{r}}$ within the UFZs decreased with increasing percentage of green space. Under the greening scenario, the minimum $C_{\mathrm{r}}$ values in $\mathrm{COZ}$ and the other UFZs increased, whereas the maximum values remained unchanged.

\section{Discussion}

\section{Reliability of the simulation}

In this study, we assessed runoff reduction associated with urban green space using the SCS-CN model. This model is employed world-wide in urban hydrologic studies, and the calculation procedures in the present study were strictly in accordance with the standard SCS-CN equations (NRCS, 1986). The model input parameters were determined in accordance with actual field data for rainfall and soil type. Thus, the approach to modeling is considered credible and the data used were appropriate and representative.

Because the entire study area is ungauged, it is difficult to obtain field or laboratory data to determine the actual amount of runoff reduction associated with urban green space. Therefore, we assessed the accuracy of our results by comparison with a similar study conducted in Beijing. Zhang et al. (2012) estimated the rainwater reduction capacity of urban green spaces in Beijing to be $2494 \mathrm{~m}^{3}$ /ha green space in 2009, in contrast to our result of $4258 \mathrm{~m}^{3} /$ ha green space in 2012. This discrepancy can be explained from several perspectives. First, the annual precipitation in 2012 was $63.66 \%$ greater than that in 2009 (Zhang et al., 2012). As demonstrated by the present results, higher rainfall results in greater retention of surface runoff by green space. Secondly, based on the runoff coefficients for various land surfaces determined by Sjöman and Gill (2013), impervious surfaces experience larger increases in runoff coefficient with increasing rainfall than green space. The runoff reduction formula (Eqn. (4)) therefore suggests that more rainwater runoff would have been retained by green space in 2012 compared to 2009.

\section{Benefits of runoff reduction by urban green spaces}

Consistent with previous studies (Matteo et al., 2006; Gill et al., 2007), our modeling work suggests that planning for urban green space offers significant potential for reducing surface runoff. Adding nearly $11 \%$ tree canopy resulted in a $>30 \%$ increase in $\Delta V$ over the entire study area. In particular, the "urban green zones" (i.e., REZ, PRZ, and AGZ) that made up only $15.54 \%$ of the total area contributed nearly $31.07 \%$ of $\Delta V$. For the "developed function zones" (i.e., LRZ, HRZ, INZ, PSZ, GOZ, and COZ) with higher runoff risk, greening improved $\Delta V$ within these UFZs, greatly reducing potential runoff risks. Particularly for HRZ and COZ, the increases in TGA (2678.3 and 2044.0 ha, respectively) would not only relieve excess runoff but also improve the environment for citizens, providing a more comfortable microclimate and esthetics (Jim and Chen, 2009; Millward and Sabir, 2011).

By reducing runoff, urban green space functions similarly to retention/detention facilities. Reduced surface runoff alleviates pressure on the urban rainwater collection system and decreases the frequency of urban pluvial flood hazards. For future municipal planning, therefore, reduction in runoff by green space can provide replacement value by reducing the required density and the capacity of drainage systems. In other words, planting more trees in urban areas can reduce the expenditure on flood control and water treatment infrastructure (Xiao and McPherson, 2002; Zhang et al., 2012). The economic value of these benefits was estimated to be $\$ 1.44 \mathrm{~m}^{-3}$ based on the unit cost of reservoir construction and the price of reclaimed water in Beijing (Zhang et al., 2012). Thus, the total economic value of runoff reduction offered by urban green space in our study area was $\$ 0.14$ billion in 2012 , increasing to $\$ 0.19$ billion under the urban greening scenario. These substantial economic benefits help to compensate for the cost of constructing urban green space and its subsequent routine maintenance. Moreover, they provide affirmative and quantitative investment opportunities for urban managers and stakeholders considering future green planning.

\section{Factors affecting potential runoff reduction by urban green space}

Regardless of the scenario, the entire study area showed similar hydrologic trends with increasing rainfall depth, indicating that $\Delta V$ was clearly dependent on the size of the rainfall event (Fig. 3), that is, the more rainfall, the more rainwater retained.

However, trends in $C_{\mathrm{r}}$ require further evaluation. Even with widespread urban greening, the $C_{\mathrm{r}}$ decreased when the rainfall was $>30 \mathrm{~mm}$. This decline mainly resulted from urban green space reaching its field capacity during larger rainfall events and then releasing the excess surface water more quickly. Decreases in canopy interception (particularly by tree canopies) during heavier rainfall events could also explain the decrease in $C_{\mathrm{r}}$ (Xiao and McPherson, 2002). Meanwhile, AMC has a significant impact on runoff reduction, as shown in our findings (Fig. 5). Conditions of lower soil-moisture represent greater potential for rainwater retention. These results suggest that the effectiveness of urban green space on runoff mitigation may be weakened particularly when it suffers from extreme rainfall events or continuous rainy weather.

$C_{\mathrm{r}}$ was lower for UFZs such as HRZ, COZ, and INZ than for other regions. These UFZs have high density of public properties and population, suggesting higher risks in these areas and potentially greater exposure of residents and workers to latent urban floods. Records confirm that urban flooding events in Beijing have tended to occur in these zones (Beijing Water Authority, 2012). These highly vulnerable UFZs should therefore be prioritized for the construction of green space. Under the greening scenario, most of these UFBs with the highest runoff risk did achieve a higher TGA and their $C_{\mathrm{r}}$ increased significantly, indicating substantial alleviation of runoff risk (Fig. 6). Although the greening scenario, as designed, effectively improved the situation, in practice, UFZs such as HRZ, $\mathrm{COZ}$, and INZ are the core developed areas of Beijing with highrise buildings and $>70 \%$ impervious surface area. The buildings and infrastructure in these UFZs are already established and there is a limited space for planting trees. Furthermore, urban soil is less hospitable to vegetation (Bartens et al., 2009). Compaction of urban soil and frequent below-ground disturbance by construction activity hamper root growth and minimize the eco-services (e.g., runoff regulation) provided by urban afforestation (Day and Bassuk, 1994; 
Grabosky and Gilman, 2004). In addition, urban managers must evaluate the tradeoffs between the eco-benefits of urban greening compared with the high economic value of the land in these core UFZs and the resulting missed opportunities for urban development.

\section{Implications for urban green planning}

Classifying urban landscapes on an intermediate spatial level helps to translate overall goals into specific targets for ecological regeneration of urban areas. Consistent with previous studies (Pauleit and Duhme, 2000; Gill et al., 2007), we found that the $C_{\mathrm{r}}$ values for HRZ, INZ, DEZ, PSZ, GOZ, and COZ were clearly lower than those of the other zones (Fig. 6). Improving the mitigation capacities of these UFBs through constructing green space in Beijing will be a gradual process (Beijing Municipal Commission of Urban Planning, 2009). Municipal departments should give priority to UFBs that have greater drainage needs and less potential for reducing runoff. Based on our greening simulation, incremental urban green construction can effectively improve the regulation of runoff in these high-risk UFBs and narrow the differences in TGA. However, considering the factors restricting the expansion of urban green spaces, municipal departments will need to adopt a series of complementary compensatory solutions to reduce risks from rainwater runoff.

For developed UFZs, managers should utilize all opportunities to add distributed and cost-effective rainwater regulation infrastructures at the UFB level, which function similarly to urban green space, as additional or compensatory measures for mitigating surface runoff. For example, roof rainwater harvesting, a decentralized solution for urban water resources management and flood control, can be applied equally to new development, retrofits, and redevelopment projects without occupying additional city land. This approach has been employed globally as an efficient and lowcost water management solution (Krishna, 2003; Kim and Furumai, 2012). In Beijing, annual rainfall runoff from building roofs accounts for nearly $64 \%$ of the total runoff from urban area and its volume was reported as increasing by $20 \%$ annually with urbanization (Che et al., 2001). The prevalence of flat roofs on both residential and commercial buildings in the city is conducive to large-scale roof harvesting of rainwater (Carter and Jackson, 2007). Widespread implementation of roof harvesting in Beijing with appropriate modification of existing buildings could function similarly to green space in reducing runoff, in addition to providing rainwater for daily consumption.

For the greened UFZs in our study area (i.e., REZ, PRZ, and AGZ), considered the main ecological conservation zones in Beijing, adaptive strategies for runoff mitigation should focus on in-fill and internal restructuring of existing open space. Existing large open spaces account for 1778.9 ha of bare land and 7534.9 ha of lawn, and therefore have great potential for development and improvement of green space. In comparison to single-layered vegetation cover, green space with a composite structure (including trees, shrubs, and lawns) can retain four to five times greater volume of rainwater at lower maintenance costs (about one-third that of lawn maintenance) (Reid et al., 1999). Assuming that the chosen tree species are well-adapted to local growing conditions, evergreen species, and in particular coniferous species, are more effective than deciduous trees in the long term, offering greater rainwater interception and evaporation year-round (Xiao and McPherson, 2002; Inkiläinen et al., 2013) and providing enhanced runoff mitigation capacity in humid weather. Furthermore, a variety of supplementary costeffective rainwater control and harvesting measures for these green open spaces can be adopted, such as infiltration trenches that can hold more than $1.67 \mathrm{~m}^{3}$ rainwater $/ \mathrm{m}^{2}$ (Pauleit and Duhme, 2000). Adopting measures that emphasize the role of urban green space in managing rainwater can partially offset the need for urban water collection and treatment infrastructure.

\section{Uncertainties and limitations of this study}

The main aims of this study were to examine the general benefits of runoff reduction provided by urban green space and its distribution pattern at multiple scales in Beijing. Use of the SCS-CN method for modeling is considered a valid time- and resourceefficient approach to achieve these goals, and the simulation results were consistent with other study. However, there are some uncertainties associated with this approach. First, the simplicity of the model itself poses substantial limitations for further study, because of the generalized use of environmental factors and the lack of physical representativeness, thereby hindering more precise simulations for use in detailed urban project planning. Many important factors affecting the reduction of rainwater runoff by urban green space should be taken into account in more specific and mechanistic research, such as the vegetation architecture, evapotranspiration from both soil and vegetation, and various meteorological factors (Sanders, 1986; Xiao and McPherson, 2002). Secondly, image-based identification for urban green space may cover a large fraction of tree canopy overlays with impervious land surface (Xiao and McPherson, 2002; Inkiläinen et al., 2013). Runoff generated from these areas will be underestimated if assigned with the same $C N$ to the tree canopy over the lawns or farmland. Furthermore, due to a lack of comprehensive urban survey data, our research did not take into account the detailed underlying surface arrangement (i.e., directly connected impervious surface, indirectly connected impervious surface, and pervious surface), which has a substantial effect on urban watershed hydrology (Schueler, 1994). Therefore, a physical-based distributed water-balance model combined with detailed urban landscape survey data would be appropriate for exploring the optimal arrangement of green space for urban water management (Roy et al., 2012).

\section{Conclusions}

In this study, we try to quantify and highlight the potential reduction effect of green space on urban runoff within the fifth ring road of Beijing. Hypothesized scenario analysis suggested that urban greening construction might greatly improve rainwater regulation. As an incremental approach to the overall goal of urban green, UFZs/UFBs with the greatest vulnerability and highest runoff risk should be prioritized for greening, which help to alleviate flooding disasters. However, the constraints of urban morphology and green space dictate that planning strategies must reflect local conditions. Considering these limitations, distributed hydrological management measures would be effective supplements for urban green space, particularly in highly developed areas. In-fill and internal restructuring of urban green areas are also essential for urban rainwater regulation and ecological conservation. Moreover, further research is needed on the implementation of specific urban rainwater management approaches, incorporating more detailed consideration of local environmental and socio-economic conditions. Our results may provide an important guidance to city managers for future urban green planning, and hope to be enhanced by linking these environmental attributes to indicators of human wellbeing.

\section{Acknowledgments}

We thank two anonymous reviewers for their constructive comments, which improved the overall quality of the manuscript. This work was financially supported by the Key Project of the National 
Natural Science Foundation of China (41230633) and the Innovation Project of the State Key Laboratory of Urban and Regional Ecology of China (SKLURE2013-1-02).

\section{References}

Armson, D., Stringer, P., Ennos, A., 2013. The effect of street trees and amenity grass on urban surface water runoff in Manchester, UK. Urban For. Urban Green. 12 282-286.

Atkinson, S., 2012. A Storm Water Runoff Investigation using GIS and Remote Sensing. University of North Texas.

Baker, T.J., Miller, S.N., 2013. Using the Soil and Water Assessment Tool (SWAT) to assess land use impact on water resources in an East African watershed.J. Hydrol. 486, 100-111.

Bartens, J., Day, S.D., Harris, J.R., Wynn, T.M., Dove, J.E., 2009. Transpiration and root development of urban trees in structural soil stormwater reservoirs. Environ. Manage. 44, 646-657.

Beijing Municipal Commission of Urban Planning, 2009. The Green Space System Planning of Beijing, Retrieved December 2013 from http://www.bjghw.gov.cn/web/static/articles/catalog_30100/article ff8080812ac7af9e012ac8ecc5c10055/ff8080812ac7af9e012ac8ecc5c10055. html (in Chinese).

Beijing Statistical Bureau, 2012. Beijing Statistical Yearbook 2012. China Statistics Press, Beijing.

Beijing Water Authority, 2012. The waterlogging locations of Beijing, Retrieved December 2013 from http://www.bjfx.gov.cn/ssxx/indexjs.htm?index=4 (in Chinese).

Bonan, G.B., 2002. Ecological Climatology: Concepts and Applications. Cambridge University Press.

Boughton, W., 1989. A review of the USDA SCS curve number method. Soil Res. 27, $511-523$.

Brander, K.E., Owen, K.E., Potter, K.W., 2004. Modeled impacts of development type on runoff volume and infiltration performance. J. Am. Water Resources Assoc. 40, 961-969.

Carter, T., Jackson, C.R., 2007. Vegetated roofs for stormwater management at multiple spatial scales. Landsc. Urban Plann. 80, 84-94.

Che, W., Wang, H., Ren, C., Liu, H., Meng, G., 2001. Research on the urban roof rainfallrunoff pollution and its utilization of Beijing city. China Water Wastewater 17, 57-61 (in Chinese, with English summary)

Chen, A., Yao, L., Sun, R., Chen, L., 2014. How many metrics are required to identify the effects of the landscape pattern on land surface temperature? Ecol. Indicators $45,424-433$.

China Meteorological Administration, 2012. Daily precipitation, Retrieved December 2013 from http://cdc.cma.gov.cn/home.do (in Chinese).

Costa, M.H., Botta, A., Cardille, J.A., 2003. Effects of large-scale changes in land cover on the discharge of the Tocantins River, Southeastern Amazonia. J. Hydrol. 283, 206-217.

Day, S.D., Bassuk, N.L., 1994. Effects of soil compaction and amelioration treatments on landscape trees. J. Arboricult. 20, 9-L9.

Ebrahimian, M., Nuruddin, A.A., Soom, M.M., Sood, A., 2012. Application of NRCScurve number method for runoff estimation in a mountainous watershed. Caspian J. Environ. Sci. 10, 103-114.

El-Hames, A.S., 2012. An empirical method for peak discharge prediction in ungauged arid and semi-arid region catchments based on morphological parameters and SCS curve number. J. Hydrol. 456, 94-100.

Fan, F., Deng, Y., Hu, X., Weng, Q., 2013. Estimating composite curve number using an improved SCS-CN method with remotely sensed variables in Guangzhou, China. Remote Sens. 5, 1425-1438.

Fu, S., Wang, H., Wang, X., Yuan, A., Lu, B., 2013. The runoff curve number of SCSCN method in Beijing. Geograph. Res. 32, 797-807 (in Chinese, with English summary).

Gill, S., Handley, J., Ennos, A., Pauleit, S., 2007. Adapting cities for climate change: the role of the green infrastructure. Built Environ. 33, 115-133.

Grabosky, J., Gilman, E., 2004. Measurement and prediction of tree growth reduction from tree planting space design in established parking lots. J. Arboricult. 30, 154-164.

Inkiläinen, E.N., McHale, M.R., Blank, G.B., James, A.L., Nikinmaa, E., 2013. The role of the residential urban forest in regulating throughfall: a case study in Raleigh, North Carolina, USA. Landsc. Urban Plann. 119, 91-103.

Jha, A.K., Bloch, R., Lamond, J., 2012. Cities And Flooding: A Guide To Integrated Urban Flood Risk Management For The 21st Century. World Bank Publications.

Jim, C.Y., Chen, W.Y., 2009. Ecosystem services and valuation of urban forests in China. Cities 26, 187-194.

Kadam, A.K., Kale, S.S., Pande, N.N., Pawar, N., Sankhua, R., 2012. Identifying potential rainwater harvesting sites of a semi-arid, basaltic region of western India, using SCS-CN method. Water Resources Manage. 26, 2537-2554.
Kim, J., Furumai, H., 2012. Assessment of rainwater availability by building type and water use through GIS-based scenario analysis. Water Resources Manage. 26 1499-1511.

Krishna, H., 2003. An overview of rainwater harvesting systems and guidelines in the United States. In: Proceedings of the First American Rainwater Harvesting Conference, pp. 21-23.

Leopold, L.B., 1968. Hydrology for Urban Land Planning: A Guidebook on the Hydrologic Effects of Urban Land Use. United States Department of the Interior.

Matteo, M., Randhir, T., Bloniarz, D., 2006. Watershed-scale impacts of forest buffers on water quality and runoff in urbanizing environment. J. Water Resources Plann. Manage. 132, 144-152.

Millward, A.A., Sabir, S., 2011. Benefits of a forested urban park: what is the value of Allan Gardens to the city of Toronto, Canada? Landsc. Urban Plann. 100 $177-188$.

Mu, F., Zhang, Z., Chi, Y., Liu, B., Zhou, Q., Wang, C., Tan, W., 2007. Dynamic monitoring of built-up area in Beijing during 1973-2005 based on multi-original remote sensed images. J. Remote Sens. 11, 257-268 (in Chinese, with English summary).

NRCS, 1986. Urban hydrology for small watersheds. Technical Release 55, 2-6.

Pan, A., Zhang, S., Meng, Q., Chen, J., 2009. Initial concept of stormwater and flood management in Beijing city. China Water Wastewater 25, 9-12 (in Chinese, with English summary).

Pataki, D.E., Carreiro, M.M., Cherrier, J., Grulke, N.E., Jennings, V., Pincetl, S., Pouyat, R.V., Whitlow, T.H., Zipperer, W.C., 2011. Coupling biogeochemical cycles in urban environments: ecosystem services, green solutions, and misconceptions. Front. Ecol. Environ. 9, 27-36.

Paul, M.J., Meyer, J.L., 2001. Streams in the urban landscape. Ann. Rev. Ecol. Syst. 32 333-365.

Pauleit, S., Duhme, F., 2000. Assessing the environmental performance of land cover types for urban planning. Landsc. Urban Plann. 52, 1-20.

Reid, K.D., Wilcox, B.P., Breshears, D.D., MacDonald, L., 1999. Runoff and erosion in a piñon-juniper woodland: influence of vegetation patches. Soil Sci. Soc. Am. J. 63, 1869-1879.

Reistetter, J.A., Russell, M., 2011. High-resolution land cover datasets, composite curve numbers, and storm water retention in the Tampa Bay, FL region. Appl. Geography 31, 740-747.

Roy, S., Byrne, J., Pickering, C., 2012. A systematic quantitative review of urban tree benefits, costs, and assessment methods across cities in different climatic zones. Urban For. Urban Green. 11, 351-363.

Sanders, R.A., 1986. Urban vegetation impacts on the hydrology of Dayton, Ohio. Urban Ecol. 9, 361-376.

Schueler, T.R., 1994. The importance of imperviousness. Watershed Protection Tech niques $1,100-111$.

Singh, P.K., Yaduvanshi, B.K., Patel, S., Ray, S., 2013. SCS-CN Based Quantification of potential of rooftop catchments and computation of ASRC for rainwater harvesting. Water Resources Manage. 27, 2001-2012.

Sjöman, J.D., Gill, S.E., 2013. Residential runoff-The role of spatial density and surface cover, with a case study in the Höjeå river catchment, southern Sweden. Urban For. Urban Green. 13, 304-314.

Sun, R., Lü, Y., Chen, L., Yang, L., Chen, A., 2013. Assessing the stability of annual temperatures for different urban functional zones. Build. Environ. 65, 90-98.

Tian, G., Wu, J., Yang, Z., 2010. Spatial pattern of urban functions in the Beijing metropolitan region. Habitat Int. 34, 249-255.

Tsihrintzis, V., Hamid, R., 1997. Urban stormwater quantity/quality modeling using the SCS method and empirical equations. J. Am. Water Resources Assoc. 33, 163-176.

Van Herzele, A., Wiedemann, T., 2003. A monitoring tool for the provision of accessible and attractive urban green spaces. Landsc. Urban Plann. 63, 109-126.

Walsh, C.J., Roy, A.H., Feminella, J.W., Cottingham, P.D., Groffman, P.M., Morgan II, R.P., 2005. The urban stream syndrome: current knowledge and the search for a cure. J. North Am. Benthological Soc. 24, 706-723.

Weng, Q., 2001. Modeling urban growth effects on surface runoff with the integration of remote sensing and GIS. Environ. Manage. 286, 737-748.

Whitford, V., Ennos, A.R., Handley, J.F., 2001. "City form and natura process"-indicators for the ecological performance of urban areas and their application to Merseyside, UK. Landsc. Urban Plann. 57, 91-103.

Xiao, Q., McPherson, E.G., 2002. Rainfall interception by Santa Monica’s municipa urban forest. Urban Ecosyst. 6, 291-302.

Yang, X., You, X., Ji, M., Nima, C., 2013. Influence factors and prediction of stormwater runoff of urban green space in Tianjin, China: laboratory experiment and quantitative theory model. Water Sci. Technol. 67, 869-876.

Zhang, B., Li, W., Xie, G., Xiao, Y., 2010. Water conservation of forest ecosystem in Beijing and its value. Ecol. Econ. 69, 1416-1426.

Zhang, B., Xie, G., Zhang, C., Zhang, J., 2012. The economic benefits of rainwaterrunoff reduction by urban green spaces: a case study in Beijing, China. J. Environ. Manage. 100, 65-71. 